\title{
TYPOLOGY OF THE DYSGRAPHIA ERRORS OF BILINGUAL PUPILS (ROMA AND TURKISH ETHNICITY) OF PRIMARY SCHOOL AGE
}

\author{
Gencho Valchev ${ }^{1}$, Diyana Georgieva ${ }^{2}$, Maria Teneva ${ }^{3}$
}

\begin{abstract}
This article addresses the problems of integrating bilingual pupils (of Roma and Turkish origin) in primary school from a logopedic perspective. The main aim of the research is to compare qualitative and quantitative parameters of dysgraphia disorders and specify their types in bilingual and monolingual pupils (Bulgarians) of primary school age. The methods include exploring: basic graphic habits, phonematic perception, writing in different language situations, and identification and typology of specific dysgraphia errors according to certain criteria. The analysis indicates a similar negative trend among achievements of bilingual pupils, both Roma and Turks, whereas the monolingual learners, Bulgarians, prove to be most efficient in performing linguistic tasks. To a great extent, the results are predetermined by both the learners' ethnolinguistic affiliation and the type of settlement in which they reside. At the same time, language interference has a negative impact on bilingual pupils' attitudes and motivation to participate actively in their education and hence, it becomes a barrier to their socialization.
\end{abstract}

UDC Classification: 376; DOI: http://dx.doi.org/10.12955/cbup.v6.1255

Keywords: dysgraphia, pupils of Turkish and Roma origin, bilingualism.

\section{Introduction}

The problem of illiteracy among some ethnolinguistic communities (especially marginalized Roma) and the children leaving the education system in Bulgaria has reached epidemic proportions in recent years. The characteristics of their education and upbringing (and socialization as a whole), with conditions of bilingualism, negatively affect the speed and quality of social adaptation and accomplishment of a bilingual child in society.

Schooling has not been an integrating factor due to the difficulties experienced by children, and for some, a lack of motivation to study the Bulgarian language. This is understandable, considering only $14 \%$ of Roma children speak Bulgarian in their family situations (Simeonova, 2007). The situation for ethnic Turks is no different (especially in the compact segregated communities). The language situation in which bilingual children (Turks and Roma) are raised differs depending on the acquisition level of Bulgarian as a second language.

Speech therapy is a science that assumes to include the subject of linguistic and speech disorders, requiring both treatment and prevention. In this, bilingualism holds a specific place. The solving of problems related to bilinguals include training, education, and socialization.

\section{Literature Review}

The study involved a review of a wide range of authors' papers covering research into the problems of education, for literacy and social adaptation of bilingual children. (Kyuchukov, 2002; Hristozova, 1998; Houghton \& Zorzi, 2003; Weekes, 2005).

The viewed authors' theoretical interpretations of bilingualism infer that there are no significant differences in defining bilingualism. It is a mental mechanism (knowledge, skills, and habits) allowing the personality to fluently switch between languages depending on the linguistic situation. Though they are not opposed to each other, the authors show differences in how they define the types of bilingualism. The differences are in the criteria by which the types of bilingualism are classified and differentiated. Researchers are united on the view that bilingualism is a linguistic phenomenon with social and mental foundations and is not related to the general somatic pathogenesis of bilingual children.

Particular difficulties in acquiring a second language and achieving complete bilingualism form the interference phenomenon, which is unanimously defined as an alteration in the structure or the elements of a language influenced by another language. According to Rowse and Wilshire (2007), the interference has a broad manifestation on all levels of the language sign system in second language acquisition. Through over-differentiation, reinterpretation, and especially nondifferentiation, it starts to negatively affect the acquisition of a second language on the phonemic level, encompassing both

\footnotetext{
${ }^{1}$ Gencho Valchev, Trakia University, Pedagogy Faculty, Stara Zagora, Bulgaria, gval@abv.bg

${ }^{2}$ Diyana Georgiva, Trakia University, Pedagogy Faculty, Stara Zagora, Bulgaria, paskaldi1929@abv.bg

${ }^{3}$ Maria Teneva, Trakia University, Pedagogy Faculty, Stara Zagora, Bulgaria, m.s.teneva@abv.bg
} 
grammatical and lexical levels. Penetration of phonetic, grammatical, and lexical elements of the native language into the second one (the studied one) appears first on the oral utterance level due to oral communication forming naturally, and then the written one as a function of specialized education.

Oral language is tightly connected to written language. Writing is only a form of communication represented with graphical linguistic means. In it the sounds are replaced with letter symbols. The foundation of writing is oral language as a universal tool for communication. According to the leading authors in this research field, writing is acquired only on condition that language is mastered and it is in compliance with all linguistic regularities that are related to the structure of language as a sign system (Stamov, 1989). The research on the literature sources about the problems of writing acquisition and the interference in children showed that, in general, it also negatively affects the mastering of the second language on a written communication level. This problem is not valid for monolingual children because there is no second language acquisition and therefore the conditions for mixing up two different linguistic systems are not present. In acquiring the writing, an interference tendency on the phonemic level is established, i.e., with acoustic analysis and synthesis. There is a probability that monolingual children may also make dysgraphia errors (due to acquiring of new knowledge), but these manifest as another type.

The conceptual framework for the empirical thesis and solutions to the research problem is outlined in the research program and the literature sources analysis.

The main aim of this study is to analyze the quantitative and qualitative parameters of the dysgraphia errors made by bilingual pupils (ethnic Roma and Turks) and to identify their specific error types compared to those of monolingual pupils (Bulgarians).

\section{Data and Methodology}

The aims of the study were achieved through the following:

- Develop a conceptual framework and terminology for the study;

- Analyze of the specialized literature on the problem of the logopedic aspects of the relationship between bilingualism and dysgraphia and the correlation between them;

- Develop a methodology adequate for the purpose of the study;

- Select participants for the study;

- Compare the dysgraphia errors of the study group (bilingual pupils) with the dysgraphia errors of the control group (monolingual pupils);

- Analyze empirical data from the study and forming of scientific and practical conclusions.

This logopedic study examined the writing style and output of bilingual pupils of Turkish and Roma ethnicity in Grades 3 and 4.

The study subject was the typology of dysgraphia errors by the study pupils when completing written assignments.

Pupils from the 3rd and 4th grade of general education schools in Bulgaria were grouped in accordance with the different types of settlements: Type 1 for a large city, Type 2 for a small town, and Type 3 for the village. The total number of pupils, 548, was divided into two large groups: bilinguals (Roma and Turks) and monolinguals (Bulgarians). The study participants were defined by indicators of population, ethnicity, age, class, and gender. The total number of bilingual pupils with Roma origin was 161 (73 girls and 88 boys), and the bilingual ethnic Turks 146 (70 girls and 76 boys). The Bulgarians were 241, of which 138 were girls and 103 boys. The regions where the study was conducted were specifically selected. They had a compact bilingual population (of Roma and Turkish ethnic origin), which allowed inclusion of both integrated (cities and small towns) and segregated classes (rural schools with predominantly bilingual population). The pupils in the study groups were placed in relatively equal conditions in which the influence of ethnocultural, socio-cultural and socioeconomic factors were limited to retain the "purity" of the results. Segregated classes had a monoethnic composition,Turks or Roma. Outside of school, the participants used only the language (dialect) of their ethnic community for communication. The control group consisted of pupils from Bulgarian ethnic origin (monolinguals) from the same classes as the study group. The 'mother' language of the 
control group was Bulgarian. The intellectual status of the pupils in the study was within the perceived norms.

The experimental study consisted of verbal stimuli in Bulgarian that was divided into two written assignments of varying degrees of complexity: a transcript of a text and an auditory dictation. The teacher explained the instructions for the tasks to avoid uncertainty. The linguistic assignments included all levels of the hierarchical structure of the language graphic system. The verbal material (texts) was consistent with the age and cognitive abilities of the pupils. Identification and typology of the dysgraphia errors were based on the following classification criteria:

- Dysgraphia errors of the spatial, coordination, and motor type were assessed as spatial coordination and positioning of letters (VSCPL) with typology of vertical (VSCPL-1), horizontal (VSCPL-2), connection (VSCPL-3); as letter-writing errors (WL); or as typology of missing items (WL-1), unnecessary items (WL-2), misspellings (WL-3), or mirror writing (WL-4).

- Dysgraphia errors of the analytic-synthetic type included omitting letters in a word (ASDE-1), adding extra letters to a word (ASDE-2), replacing one letter with another one (ASDE-3), omitting syllables in a word (ASDE-4), adding extra syllables in a word (ASDE-5), replacing syllables (ASDE6), merging words (ASDE-7), and failing to finish a word (ASDE-8).

The variability within the data was assessed in variance analyses - descriptive statistics: Mean, Std. Deviation, Std. Error, Minimum, Maximum; The level of Confidence Interval - 95\%), alternative analyses (Relative share and frequency of errors made; distribution of pupils with errors according to pre-set criteria), and comparative analyses (Comparing arithmetic means and confidence interval parameters for the average error level and its variations for each of the types of dysgraphia errors of the pupils in the control and the experimental groups), using the Statistical Package for Social Science, SPSS 16,0. The results were evaluated according to the quantitative and qualitative criteria of the diagnostic procedure for identification and typology of specific dysgraphia errors in bilingual pupils. For each linguistic test, the analyses were separated by the following divisions:

- Students who displayed dysgraphia errors according to the indices of an ethnic group, gender, age, grade, and type of settlement; and Errors according to typology.

\section{Results and Discussion}

The results of the linguistic test, Transcript of a Text, showed several tendencies.

According to the ethnic group's language status index, the largest number of errors, 1258 (54.1\%), was recorded among Roma children. This outcome was more than half of all errors recorded (2325). The next largest number of errors, 803 (34.5\%), was recorded among Turkish pupils. In the control group, the Bulgarian children were the most successful, with a total of 264 errors (11.4\%). The distribution of the dysgraphia errors according to gender was also unbalanced. Twice more errors were established among the boys, $1561(67.2 \%)$ then the girls $(32.8 \%)$. The age factor was also salient. The most predominant number of errors was observed among the 10-year-old pupils (47.3\%). Pupils at the age of 9 and 11 years formed a homogenous group with their similar results $(26.5-26.2 \%)$. No errors were observed among the 12-year-old pupils. The type of settlement was significant in the arrangement of dysgraphia errors. In this, the fewest errors were found among pupils who inhabited large cities, i.e., $19.5 \%$. These errors were made by 27 children, equating to 16.7 errors on average per pupil. Twice larger is the share of errors demonstrated by small-town pupils, $41.1 \%$ (made by 31 pupils), and the pupils who live in village areas, 39.4\% (made by 37 pupils). This means that, on average, 30.8 errors are made by the small-town pupils and for the pupils from the villages this number was 24.7. Figure 1 shows the distribution of the errors depending on the pupil's grade. The monolingual pupils had identical results for the 3rd and 4th grade, while in the group of bilingual children the dominant position changed according to the grade.

The classification of errors according to types is shown in Table 1A and Table 1B.

All three ethnic groups displayed dysgraphia errors of both types, i.e., errors in the spatial coordination and positioning of the letters (VSCPL) and in the writing of the letters (WL).

Overall, in the control group, the majority of errors were related to the spatial coordination and positioning of the letters, while among the Turkish and Roma children the most frequent errors were those of representing the written symbols in the graphical grid. 


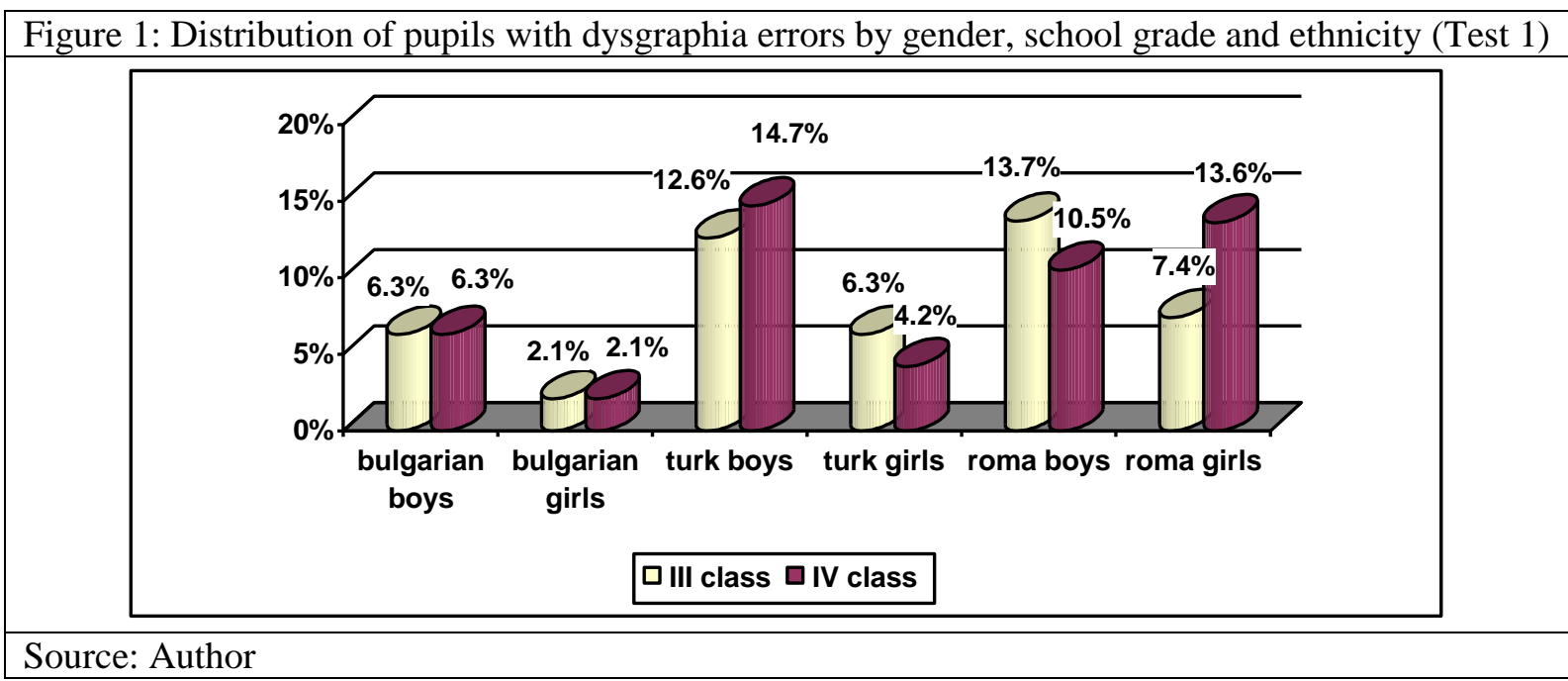

Table 1A: Distribution of dysgraphia errors by typology and ethnicity and language status (Test 1)

\begin{tabular}{|c|c|c|c|c|c|c|c|c|}
\hline Ethnicity & Statistic & VSCPL1 & VSCPL2 & VSCPL3 & WL1 & WL2 & WL3 & WL 4 \\
\hline \multirow[t]{4}{*}{ Bulgarians } & Sum & 54 & 44 & 44 & 12 & 17 & 84 & \\
\hline & $\%$ of Total Sum & 19.01 & 12.98 & 9.44 & 5.24 & 6.64 & 12.54 & \\
\hline & $\%$ of Total $\mathrm{N}$ & 14.29 & 10.14 & 12.99 & 7.55 & 8.33 & 13.95 & \\
\hline & $\mathrm{N}$ cases & 9 & 7 & 10 & 4 & 5 & 12 & \\
\hline \multirow[t]{4}{*}{$\begin{array}{l}\text { Ethnic } \\
\text { Turks }\end{array}$} & Sum & 81 & 113 & 174 & 80 & 102 & 227 & \\
\hline & $\%$ of Total Sum & 28.52 & 33.33 & 37.34 & 34.93 & 39.84 & 33.88 & \\
\hline & $\%$ of Total N & 33.33 & 39.13 & 36.36 & 32.08 & 35.00 & 36.0 & \\
\hline & $\mathrm{N}$ cases & 21 & 27 & 28 & 17 & 21 & 31 & \\
\hline \multirow[t]{4}{*}{ Ethnic Roma } & Sum & 149 & 182 & 248 & 137 & 137 & 359 & 10 \\
\hline & $\%$ of Total Sum & 52.46 & 53.69 & 53.22 & 59.83 & 53.52 & 53.58 & 100.00 \\
\hline & $\%$ of Total $\mathrm{N}$ & 52.38 & 50.7 & 50.65 & 60.38 & 56.67 & 50.00 & 100.00 \\
\hline & $\mathrm{N}$ cases & 33 & 35 & 39 & 32 & 34 & 43 & 2 \\
\hline
\end{tabular}

Table 1B: Distribution of dysgraphia errors by typology and ethnicity and language status (Test 1)

\begin{tabular}{|c|c|c|c|c|c|c|c|}
\hline Ethnicity & Statistic & ASDE1 & ASDE2 & ASDE3 & ASDE4 & ASDE7 & ASDE8 \\
\hline Bulgarians & Sum & & & & & 9 & \\
\hline & \% of Total Sum & & & & & 56.25 & \\
\hline & \% of Total N & & & & & 50.00 & \\
\hline & N cases & & & & & 1 & \\
\hline $\begin{array}{c}\text { Ethnic } \\
\text { Turks }\end{array}$ & Sum & 7 & 6 & 6 & & & 7 \\
\hline & \% of Total Sum & 58.33 & 66.67 & 37.50 & & & 50.00 \\
\hline & \% of Total N & 50.00 & 66.67 & 33.33 & & & 50.00 \\
\hline & N cases & 2 & 2 & 1 & & & 2 \\
\hline Ethnic Roma & Sum & 5 & 3 & 10 & 4 & 7 & 7 \\
\hline & $\%$ of Total Sum & 41.67 & 33.33 & 62.50 & 100.00 & 43.75 & 50.00 \\
\hline & $\%$ of Total N & 50.00 & 33.33 & 66.67 & 100.00 & 50.00 & 50.00 \\
\hline & N cases & 2 & 1 & 2 & 1 & 1 & 2 \\
\hline
\end{tabular}

Source: Author

The quantity of the analytic-synthetic errors (ASDE) was largely reduced among the representatives of the two genders in comparison with the VSCPL and WL types of errors. This linguistic test found no analytic-synthetic dysgraphia errors of ASDE 5 and ASDE 6 (Table 1). 
The share of all the types of dysgraphia errors was the largest, within the limits of the confidence interval, in the control group of monolingual Bulgarians. Apart from the differences between the control and the experimental group, there were also differences between the bilingual subgroups (Turkish and Roma children). The share of the Turkish children, within the limits of the confidence interval, was larger than that of the Roma children in relation to all types of errors.

Comparing the results after the second linguistic assignment, Auditory Dictation, reveals that, apart from gender, the distribution of dysgraphia errors according to the ethnic or language status, age and type of settlement is similar to the dynamics of the first written task (Figure 2).

As far as the ethnicity or language status indicator is concerned, Roma pupils made markedly more errors then the rest of the groups (50,04\%). Pupils of Turkish origin were next $(37,25 \%)$, whereas the results of Bulgarians in the control group were sharply different from those of the other two groups (8,71\% of all errors). As mentioned earlier, gender was an important factor in the pupils' accomplishments. Errors by boys in the Auditory Dictation reached 59,93\%, while errors by girls $40,07 \%$. While the boys retained the status quo in the number of errors between the two tasks, the girl's results changed with the number of errors increasing by almost a third in the second task. Hence, the auditory dictation appeared to be more difficult for female participants than the males.

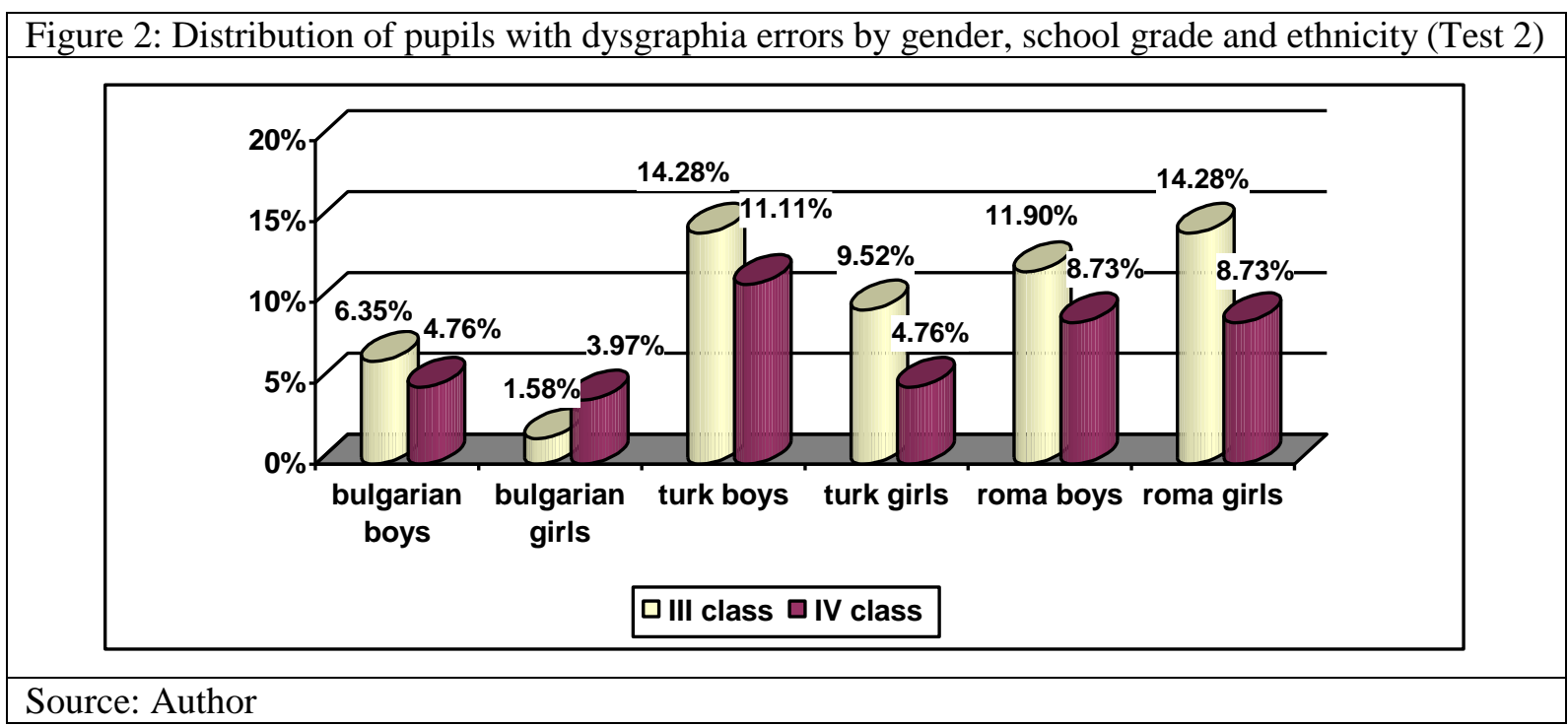

There is again a strong dependence of the second subtest results on the age of the population. Most of the dysgraphia errors were observed in 10 -year-old pupils ( $48.51 \%$ of all errors). A similar percentage ratio is recorded for 9 and 11-year-old pupils (24.83\% and $26.66 \%$ respectively).

Clearly, the type of settlement has a strong effect on the performance of the study participants. The fewest errors are noted in pupils living in large cities, i.e., $20.02 \%$ of all errors. The number almost doubles in pupils residing in small towns (37.59\%) and those living in rural municipalities $(42.40 \%)$. With small variations, the result confirms the trend observed in the first subtest. As far as the grade criterion was concerned, the dysgraphia errors of grade 3 pupils constituted $57.14 \%$, whereas grade 4 pupils were somewhat behind this with $42.86 \%$.

The implementation of the second linguistic assignment reveals the types of dysgraphia errors in the pupils of this study (Table 2A, Table 2B).

Importantly, errors of the analytic-synthetic type showed a visible increase in both genders compared to those of the graphics-related errors (VSCPL and WL). The percentage of the same dysgraphia errors (VSCPL and WL) was higher for the nine-year-old (65.85\%) and ten-year-old participants $(62.76 \%)$. This results contrast to the ASDE errors for nine-year-old $(34.15 \%)$ and ten-year-old children (47.24\%). The relative shares of error types in 11-year-old pupils were almost equal at $49.57 \%$ (VSCPL and WL) and 50.43\% (ASDE). Regarding the type of settlement, results indicated an increase in analytical and synthetic errors (ASE) in all three population groups: large city, small town, and village. 


\begin{tabular}{|c|c|c|c|c|c|c|c|c|}
\hline Ethicity & Statistc & VSCPL1 & VSCPL2 & VSCPL3 & WL 1 & WL 2 & WL3 & $\overline{\text { WL } 4}$ \\
\hline \multirow[t]{4}{*}{ Bulgarians } & Sum & 29 & 23 & 25 & 9 & 10 & 47 & 2 \\
\hline & $\%$ of Total Sum & 14.50 & 9.66 & 7.67 & 5.20 & 5.32 & 10.73 & 25.00 \\
\hline & $\%$ of Total N & 1.64 & 8.45 & 12.50 & 7.27 & 8.33 & 13.64 & 33.33 \\
\hline & $\mathrm{N}$ cases & 9 & 6 & 10 & 4 & 5 & 12 & 1 \\
\hline \multirow[t]{4}{*}{$\begin{array}{l}\text { Ethnic } \\
\text { Turks }\end{array}$} & Sum & 53 & 85 & 123 & 61 & 74 & 164 & \\
\hline & $\%$ of Total Sum & 26.50 & 35.71 & 37.73 & 35.26 & 39.36 & 37.44 & \\
\hline & $\%$ of Total N & 31.82 & 38.03 & 35.00 & 30.91 & 35.00 & 35.23 & \\
\hline & $\mathrm{N}$ cases & 21 & 27 & 28 & 17 & 21 & 31 & \\
\hline \multirow[t]{4}{*}{ Ethnic Roma } & Sum & 18 & 130 & 178 & 103 & 104 & 227 & 6 \\
\hline & $\%$ of Total Sum & 59.00 & 54.62 & 54.60 & 59.54 & 55.32 & 51.83 & 75.00 \\
\hline & $\%$ of Total N & 54.55 & 53.52 & 52.50 & 61.82 & 56.67 & 51.14 & 66.67 \\
\hline & $\mathrm{N}$ cases & 36 & 38 & 42 & 34 & 34 & 45 & 2 \\
\hline
\end{tabular}

\begin{tabular}{|c|c|c|c|c|c|c|c|c|c|}
\hline Ethnicity & Statistc & $\begin{array}{c}\text { ASDE } \\
1\end{array}$ & ASDE2 & ASDE3 & ASDE4 & ASDE5 & ASDE6 & ASDE7 & ASDE8 \\
\hline \multirow[t]{4}{*}{ Bulgarians } & Sum & 36 & 12 & 8 & 1 & & & 9 & 17 \\
\hline & $\%$ of Total Sum & 18.46 & 8.00 & 3.60 & 0.91 & & & 11.54 & 8.10 \\
\hline & $\%$ of Total $\mathrm{N}$ & 17.98 & 9.52 & 4.76 & 1.96 & & & 6.12 & 11.65 \\
\hline & $\mathrm{N}$ cases & 16 & 8 & 4 & 1 & & & 3 & 12 \\
\hline \multirow[t]{4}{*}{$\begin{array}{l}\text { Ethnic } \\
\text { Turks }\end{array}$} & Sum & 63 & 57 & 111 & 41 & 10 & 39 & 22 & 72 \\
\hline & $\%$ of Total Sum & 32.31 & 38.00 & 50.00 & 37.27 & 38.46 & 69.64 & 28.21 & 34.29 \\
\hline & $\%$ of Total $\mathrm{N}$ & 35.96 & 40.48 & 46.43 & 39.22 & 35.00 & 65.9 & 36.3 & 40.78 \\
\hline & $\mathrm{N}$ cases & 32 & 34 & 39 & 20 & 7 & 25 & 18 & 42 \\
\hline \multirow[t]{4}{*}{$\begin{array}{l}\text { Ethnic } \\
\text { Roma }\end{array}$} & Sum & 96 & 81 & 103 & 68 & 16 & 17 & 47 & 121 \\
\hline & $\%$ of Total Sum & 49.23 & 54.00 & 46.40 & 61.82 & 61.54 & 30.36 & 60.26 & 57.62 \\
\hline & $\%$ of Total $\mathrm{N}$ & 46.07 & 50.00 & 48.81 & 58.82 & 65.00 & 34.21 & 57.14 & 47.57 \\
\hline & $\mathrm{N}$ cases & 41 & 42 & 41 & 30 & 13 & 13 & 28 & 49 \\
\hline
\end{tabular}

In summary, the research established the following. Concerning the control group (monolinguals), within the specified confidence interval, the pupils of Bulgarian origin had the greatest share of dysgraphia errors across all types examined.

Differences were also observed between the two subgroups of bilinguals (Turks and Roma). Within the specified confidence interval, pupils of Turkish origin had the greater percentage of errors across all types, apart from these four: VSCPL 1, VSCPL 3, ASDE 2, and ASDE 4.

The specific contrasts between the two bilingual populations are particularly noticeable here. The reason is that these errors belong to different typological groups: one related to the spatial coordination and positioning of letters (VSCPL) and the others of an analytical and synthetic nature (ASDE). An interesting regularity was observed: in the analytic and synthetic errors, with a proportion of Roma, above the upper limit, higher than that of Turks.

Participants in the control group who had made analytical and synthetic errors in the Auditory Dictation subtest constituted the smallest part of those above the upper limit of the confidence interval. In the group of bilingual pupils, this indicator was considerably higher for each type of error.

\section{Conclusion}

In summary, the results show similar trends for both written tasks, the transcript of a text and the auditory dictation. The largest number of errors was associated with the representation of graphical 
signs and those referring to the spatial coordination and positioning of letters, rather than those relating to analytic-synthetic types, of which the number was very small. Pupils in the control group mainly presented errors of the second type, whereas the bilingual pupils were characterized by errors of the first type. Analytic-synthetic errors predominated in the experimental group. The result can be explained by the groups low level of linguistic competence. At the same time, monolingual pupils are at an advantage when it comes to their achievements.

The linguistic environment in which pupils live and grow and the type of settlement seem to be the most influential factors on their verbal (written) skills. An explanation for the existing differences specific to the dysgraphia errors can be traced to the lack of supportive mechanisms for the two linguistic systems in communicating, on the one hand, and on the other, to the high degree of segregation and absence or existence of limited linguistic contacts in the integrative environment, and the insufficient verbal communication outside of their own socio-ethnic or linguistic group.

The language interference in bilingual children affects the whole verbal communication, oral and written. Because written language has a firmer normativity in its realization, it is acquired in a slower and more complex manner. Therefore, the risk of difficulties in its acquisition is higher. A bilingual child needs to make longer and more purposeful efforts to form graphical skills, to build the necessary vocabulary, acquire the particular styles and grammatical rules of a certain language, and than apply them adequately in written practice.

\section{References}

Houghton, G., \& Zorzi, M. (2003). Normal and impaired spelling in a connectionist dual-route architecture. Cognitive Neuropsychology, 20, 115-162.

Hristozova, G. (1998). Spelling education in elementary classes. Plovdiv.

Kyuchukov, H. (2002) The written Bulgarian language of Roma pupils in 3th-5th grade, S.

Rowse, H. J., \& Wilshire, C. E. (2007). Comparison of phonological and whole-word treatments for two contrasting cases of developmental dyslexia. Cognitive Neuropsychology, 24(8), 817-842.

Sebastian, R., Laird, A., \& Kiran, S. (2011) Meta-analysis of the neural representation of firs language. Applied Psycholinguistics, 32, 799-819.

Simeonova, A. I. (2007) "The Roma in Bulgaria: the new challenges", Report of Foundation "Friedrich Ebert".

Stamov, V. (1989) Logoledia. Blagoevgrad.

Weekes, W. S. (2005). Acquired disorders of reading and writing: cross-script comparisons. Behavioural Neurology, 16 (23), 51-57. 